\title{
Quantitative Assessment of State-Dependent Atmospheric Motion Vector Uncertainties
}

\author{
Derek J. Posselt, Longtao Wu, Kevin Mueller, Lei Huang, Fredrick W. Irion, \\ SHANNON BROWN, AND HUI SU \\ Jet Propulsion Laboratory, California Institute of Technology, Pasadena, California \\ DAVID SANTEK AND CHRISTOPHER S. VELDEN \\ Cooperative Institute for Meteorological Satellite Studies, University of Wisconsin-Madison, Madison, Wisconsin
}

(Manuscript received 1 July 2019, in final form 4 October 2019)

\begin{abstract}
This study examines the error characteristics of atmospheric motion vectors (AMVs) obtained by tracking the movement of water vapor features. A high-resolution numerical simulation of a dynamic weather event is used as a baseline, and AMVs tracked from retrieved water vapor fields are compared with the "true" winds produced by the model. The sensitivity of AMV uncertainty to time interval, AMV tracking window size, water vapor content, horizontal gradient, and wind structure is examined. AMVs are derived from the model water vapor field at a specific height and also from water vapor fields vertically blurred using smoothing functions consistent with high-spectral-resolution infrared (IR) and high-frequency microwave (MW) water vapor sounders. Uncertainties in water vapor AMVs are state dependent and are largest for regions with small water vapor content and small water vapor spatial gradient and in places where the flow runs parallel to contours of constant water vapor content. Smoothing of water vapor consistent with IR and MW retrievals does not increase AMV uncertainty; however, the yield of AMVs from IR sounders is much lower than from MW sounders because of the inability of IR sounders to retrieve water vapor below clouds. The yield and error are similar for AMVs in the lower and upper troposphere, even though the water vapor content in the upper troposphere is much smaller. The results have implications for the design of new observing systems, as well as the specification of errors when AMVs are ingested in data assimilation systems.
\end{abstract}

\section{Introduction}

An accurate depiction of the 3D structure of the global wind field has been highlighted as a key need in the next-generation global observing system (Zeng et al. 2016; National Academies of Sciences, Engineering, and Medicine 2018). Knowledge of the wind field is essential to our understanding of Earth's general circulation and for accurately defining the atmospheric state for initialization of numerical weather prediction models. However, the 3D structure of the global wind field is not well observed (Gentry et al. 2008). Atmospheric motion vectors (AMVs) derived from sequences of satellite images have been used for decades to assist in forecasting, weather event analysis, transport of chemical constituents, among others (Menzel 2001). Assimilation of AMVs has been shown to have a significant positive impact on forecast skill in numerical

\footnotetext{
Corresponding author: Derek J. Posselt, derek.posselt@jpl. nasa.gov
}

weather prediction (NWP) models (e.g., Berger et al. 2011; $\mathrm{Wu}$ et al. 2014). Traditionally, AMVs have been derived from geostationary satellite imagery, leveraging the high temporal and spatial resolution of modern satellite systems (Velden et al. 2005). However, in the previous two decades, sequences of images from low-Earth-orbiting satellites have also been used (primarily over the high latitudes; e.g., Key et al. 2003; Santek 2010) to produce AMVs.

While the bulk of AMV development has focused on tracking cloud features (Menzel et al. 1983; Schmetz et al. 1993; LeMarshall et al. 1994; Nieman et al. 1997), it is also common practice to track imagery from satellite channels that are sensitive to water vapor emission (Eigenwillig and Fischer 1982; Stewart et al. 1985; Holmlund 1993; Velden et al. 1997). This has enabled estimates of motion vectors in cloud free regions and has in part been fueled by the increase in availability of higher-spectral-resolution imagery, which makes it possible to track water vapor features at a greater number of layers in the troposphere. With the advent of 
geostationary hyperspectral resolution imagery, as well as the increasing feasibility of high-temporal-resolution water vapor imagery from constellations of small lowEarth-orbiting satellites, it is now conceivable to track water vapor features at multiple heights in the troposphere and to produce estimates of the three-dimensional distribution of horizontal winds. In addition to tracking features in the water vapor imagery, numerical weather prediction centers that use assimilation methodologies that explicitly incorporate time resolved information [e.g., four-dimensional variational (4DVAR; Rabier et al. 2000; Rawlins et al. 2007)] will naturally derive wind information from sequences of satellite radiances.

A critical component in the development of a new observing system for three-dimensional tropospheric winds is the accurate characterization of uncertainties in the observations. Uncertainty estimates are not only necessary for the proper use of AMVs alongside other sources of wind information but are crucial for the assimilation of AMVs in NWP systems. Previous research has explored the uncertainty characteristics of AMVs and has determined that the assignment of the vertical location of the AMV (height assignment) contributes a large component of the error (Velden and Bedka 2009; Salonen et al. 2015). This is because infrared radiances observed in a given satellite channel are emitted from a layer that varies in depth according to the concentration of the emitting gasses, as well as the temperature structure of the atmosphere. While the use of multichannel imagery and sophisticated radiative transfer have improved the height assignment for winds in cloudy regions (especially in the upper troposphere, Nieman et al. 1993), there is still large uncertainty in the assignment of heights for clear-air single-channel water vapor winds in the lower to midtroposphere (Velden and Bedka 2009). It is conceivable that tracking water vapor fields derived from high-spectral-resolution imagery moisture retrievals may help to reduce the uncertainty in AMV height assignment, as the retrieval algorithm naturally assigns a height to each layer in a water vapor profile (Santek et al. 2014).

In this study, we use a high-resolution numerical simulation of a dynamic weather event as a baseline and compare AMVs tracked from retrieved water vapor fields to the winds produced by the model (the remainder of the paper will focus on this type of AMVs). Our goal is to analyze the functional relationships in the differences between the tracked versus reference wind speeds. At the outset, we wish to clarify that the quantity we examine is the difference between the tracked winds and the reference (nature run) winds. Since we have a known reference state, we will at times refer to these differences as errors, since the differences represent a deviation from the true state. In real-world applications, for which the true wind speed is not known, these differences would be more appropriately referred to as uncertainties. As such, in places we feel the results reflect applications, we use the wording uncertainties. We explore the sensitivity of AMV uncertainty (as represented by the difference between tracked wind and model-simulated wind) to time interval and AMV tracking window size (related to AMV spatial resolution), and we explore the dependence of the uncertainty on the ambient water vapor and wind structure. Previous work has shown that the optimal window size and tracking time interval are closely related to the spatial resolution of the instrument imaging the features of interest (García-Pereda and Borde 2014). In our experiments, we first assume the vertical distribution of the water vapor field is perfectly known; as such, the results represent the best possible height assignment performance for the chosen AMV tracking algorithm. We then coarsen the water vapor fields in the vertical, consistent with simulated retrievals from current and near-future infrared and microwave sounders. We assess the degree to which coarser vertical resolution affects AMV uncertainties (including height assignment) and discuss the tradeoffs between yield and accuracy for regions without clouds and precipitation. The remainder of this paper is organized as follows. We provide a description of the tracking algorithm used to produce AMVs, and the case study simulation used as a baseline, in section 2 . Results of the analysis of AMV uncertainty are presented in section 3, and a discussion of the implications for data assimilation (DA), along with the caveats and limitations of our study, is provided in section 4. A summary and conclusions, as well as suggestions for future work, is contained in section 5 .

\section{Method}

\section{a. AMV algorithm}

Local area pattern matching is a standard approach to track cloud features in successive imagery from initial targets (the location of selected features in the first image) to displacements calculated from final targets (locations with best correlations in a subsequent image; Mueller et al. 2013). The procedure starts by interrogating an initial image and finding local two-dimensional gradients that meet thresholds (targets). These targets are then tracked (if they are coherent in time) forward/backward in subsequent/preceding images. After establishing a search area representing a range of possible target coordinate matches for each source coordinate, a cost function whose minimum represents the best match is computed throughout the search area. In our algorithm, the cost 
function is a normalized sum of absolute differences $(\mathrm{SAD})$ aggregated over a (nominally $11 \times 11$ pixels) window and computed at all discrete pixel coordinates throughout the area. The cost values on a $3 \times 3$ grid of coordinates surrounding the best discrete match are used to fit a continuous, quadratic cost function at that location. If that quadratic has a local minimum within the $3 \times 3$ grid, the tracker successfully yields the subpixel location of that minimum. If not, then the tracker yields no match, having determined the best available discrete match to be insufficiently robust. We apply our tracking algorithm to two sequential pairs of images with the center-in-time image shared between the two (i.e., an image triplet). Every possible tracking window is used over the entire spatial domain. From each pair, a center-referenced grid of wind estimates is determined. At grid points where both estimates are valid and their vector magnitude of difference is less than a height-level dependent threshold, the average is reported as the final retrieved wind. In practice, the height-level dependent threshold is computed per image triplet to be $30 \%$ of the maximum retrieved wind speed.

The key parameter that affects the performance of feature tracking for the above algorithm (and in general, since nearly all feature tracking algorithms are comparable) is the scale of the cost function aggregation (i.e., $11 \times 11$ pixels above), which we refer to as the target box. This parameter determines the horizontal scale of the features to which the algorithm is most sensitive. Additionally, this is the scale at which the algorithm assumes wind to be approximately constant (limited accelerations), defining the effective resolution of the retrieved wind. Aggregation scale can influence the signal-to-noise ratio (SNR), resulting in low SNR if too few pixels are incorporated.

\section{b. Nature runs}

We select as our reference case an extratropical cyclone (ETC) that occurred east of the United States over the western Atlantic Ocean during late November 2006. This storm has a large range of wind speeds and water vapor contents and gradients, allowing us to evaluate the error characteristics of the AMV algorithm across a broad range of atmospheric conditions. Focusing on a limited area allows us to 1) produce simulated fields at the resolution of current and near future microwave and high-spectral-resolution infrared sounders, and 2) store model output at the high temporal resolution necessary to evaluate AMVs obtained from rapid-refresh measurements of water vapor. We choose this particular ETC case as it is one that we have examined from an observational perspective in several previous studies (Posselt et al. 2008a,b; Crespo and Posselt 2016).

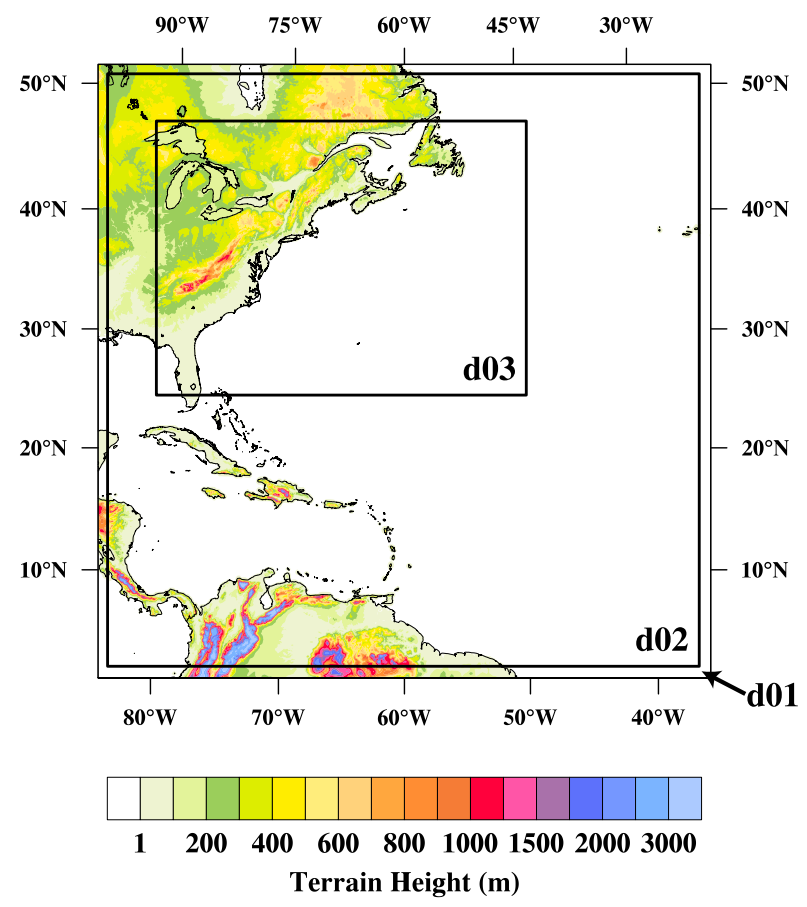

FIG. 1. Depiction of the three WRF domains used in the study, along with the terrain height (color shaded) for reference.

Simulations of this case are conducted using the Advanced Research Weather Research and Forecasting (WRF) Model, version 3.5.1 (Skamarock et al. 2008). The model is run with 3 nested domains ( $\mathrm{d} 01, \mathrm{~d} 02$, and d03) at horizontal resolutions of 20,4 , and $1.33 \mathrm{~km}$, respectively. We focus our AMV analysis on domains 2 and 3, which cover a region of approximately $5600 \mathrm{~km} \times$ $5600 \mathrm{~km}$ and $2700 \mathrm{~km} \times 2000 \mathrm{~km}$, respectively (Fig. 1). The Grell-Freitas cumulus scheme (Grell and Freitas 2014) is used in the outermost domain (d01), while no cumulus scheme is used in the two nested domains. Note that the outermost domain is not used in our analysis and serves only to buffer the inner domains from the influence of lateral boundary conditions. Other physics parameterizations used on all three domains include the WRF single-moment 6-class microphysics scheme (WSM6; Hong and Lim 2006), the Mellor-YamadaJanjić (MYJ; Janjić 1994) planetary boundary layer scheme, and the Rapid Radiative Transfer Model for general circulation models (RRTMG) shortwave and longwave radiation schemes (Iacono et al. 2008). There are 75 vertical model levels with a top at $50 \mathrm{hPa}$. The initial and boundary conditions for the model simulations are provided by the 6-hourly European Centre for Medium-Range Weather Forecasts (ECMWF) Interim reanalysis (ERA-Interim) data (Dee et al. 2011) with approximately $80-\mathrm{km}$ horizontal grid spacing. The simulation starts on 0000 UTC 21 November 2006, and d01 

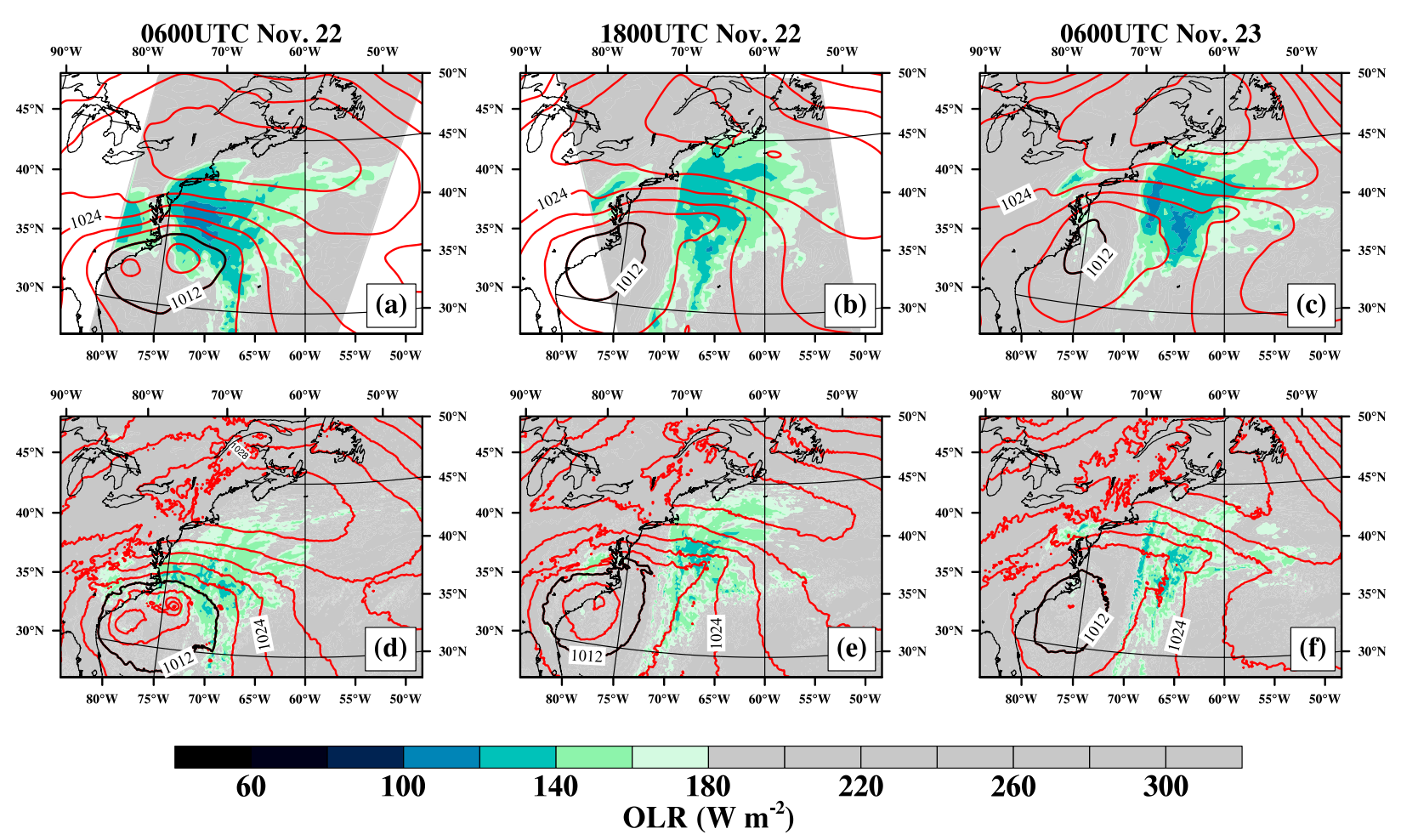

FIG. 2. Depiction of the sea level pressure fields (hPa; red unfilled contours) and outgoing longwave radiation (color shaded contours) (a)-(c) from the analysis and CERES and (d)-(f) from the inner domain (d03) of the WRF simulation. For reference, the 1012-hPa SLP contour is colored black.

and d02 domains are run continuously for $54 \mathrm{~h}$. The $1.33-$ $\mathrm{km}$ domain is run for $30 \mathrm{~h}$ starting at 0000 UTC 22 November 2006. Outputs from both domains d02 and $\mathrm{d} 03$ are saved every $5 \mathrm{~min}$.

To evaluate the robustness of the results obtained from our limited area WRF Model domain, we also conduct an analysis of AMVs obtained from the Goddard Earth Observing System Model, version 5 (GEOS-5), nature run (G5NR; Putman et al. 2014). The G5NR data have global coverage at $7 \mathrm{~km}$ horizontal resolution and are saved every $30 \mathrm{~min}$, which prevents us from using them to examine high-temporal- and spatial-resolution sensors. Our analysis shows that the optimal temporal interval for maximizing clear-sky water vapor AMV tracking accuracy depends on the horizontal resolution of the simulated moisture fields. In our preliminary analysis, we tested several grid resolutions, and found that data gridded at a reporting interval of $7 \mathrm{~km}$ required a 1-h tracking interval to achieve an RMS wind speed accuracy of $2 \mathrm{~m} \mathrm{~s}^{-1}$ or better. Thus, we apply the AMV tracking algorithm to the hourly G5NR output at 6-hourly intervals $(0000,0600,1200$, and 1800 UTC). We choose to analyze the months of July and August 2006 because these months are also used in data assimilation and observing system simulation experiments (OSSEs; results to be described in a companion paper) with GEOS-5. While the time period differs from that of the WRF case, the global simulation contains numerous tropical and extratropical storm system during July and August 2006.

We are using our simulations as a proxy for the real atmospheric state, similar to the manner in which a nature run is used in an NWP OSSE. As such, it is only necessary that the simulation produce a realistic depiction of the fields of interest (in this case, the general moisture content and storm structure), not that it reproduces the exact features that occurred in the real case. Here we present a brief comparison between the WRFsimulated sea level pressure (SLP) and outgoing longwave radiation (OLR) to show that the simulated storm had realistic dynamic and cloud fields. This comparison also introduces the general storm structure and evolution. We conduct our comparison on the innermost domain but note that an evaluation of the domain 2 fields yields similar results. We use operational analysis fields to evaluate storm dynamics, and examine OLR from Clouds and the Earth's Radiant Energy System (CERES; Loeb et al. 2018) measurements made on NASA's Aqua platform to evaluate the simulated cloud distribution.

Between 0600 UTC 22 November and 0600 UTC 23 November 2006 (Fig. 2), a surface low pressure center 
(a) IR

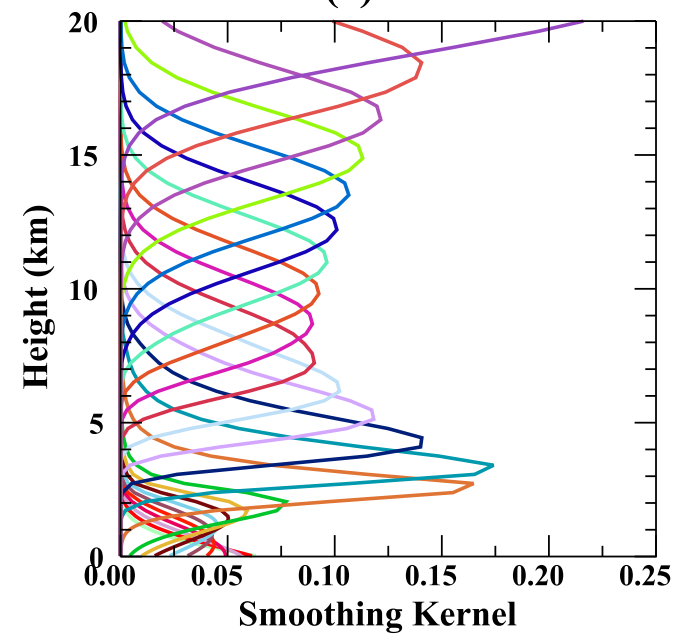

(b) Microwave

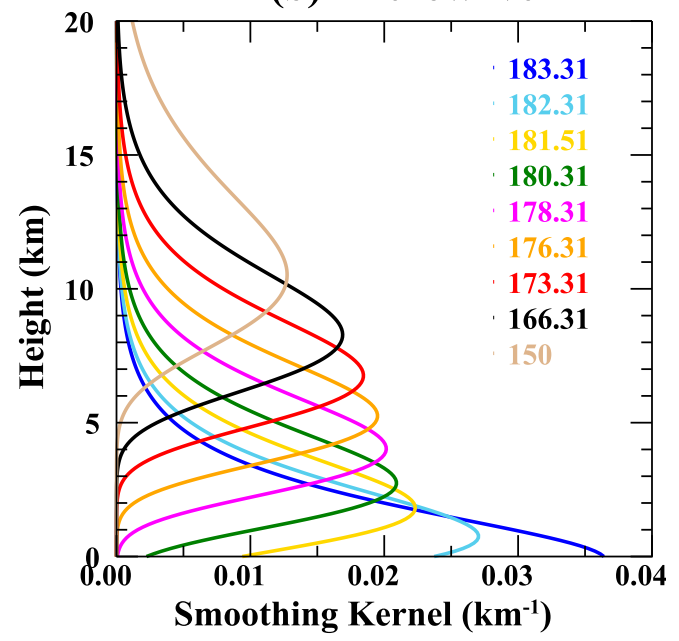

FIG. 3. Smoothing functions used to vertically blur the WRF water vapor fields for hypothetical (a) high-spectralresolution infrared and (b) microwave instruments. The colors in (b) correspond to specific MW channels, whereas those in (a) represent the aggregate of a number of hyperspectral IR channels. Note that the smoothing functions in (a) are unitless while those in (b) have units of inverse kilometers.

was located east of the Carolinas over the northwestern Atlantic Ocean. Comparison between the simulated and analyzed SLP fields show that the model placed the surface low pressure center at the correct location, and with approximately the correct magnitude, though the storm in the WRF simulation was slightly deeper than in the analysis. It is likely that the lower sea level pressures in the WRF are due to the higher resolution of the model (1.33-km horizontal grid spacing) relative to the analysis ( $80 \mathrm{~km}$ horizontal grid spacing). For reference, we have highlighted the location of the 1012-hPa SLP contour, which is in approximately the same location in the model and analysis. Clouds in the model, as depicted in the OLR, are located in approximately the correct location, and with a pattern that is similar to the observations, though the OLR values in the model appear to be systematically higher than observed. The greater degree of finescale structure in the WRF-simulated OLR is due to the finer grid spacing of the model $(1.33 \mathrm{~km})$ relative to the CERES footprint $(\sim 20 \mathrm{~km})$.

\section{c. Simulation of water vapor fields from IR and $M W$ sounders}

In real-world AMV applications, the tracking algorithm is used to produce winds from sequential water vapor fields retrieved from spaceborne sensors typically taking measurements of radiances in the infrared (IR) portion of the electromagnetic spectrum. Recent studies have also suggested that water vapor retrieved from microwave (MW)-based sounders may also be used to produce AMVs (e.g., Lambrigtsen et al. 2018). Water vapor is retrieved from these radiances with a vertical and horizontal resolution that depends on the spectral resolution and field-of-view (FOV) size of the sensor, respectively. Our aim is not to evaluate specific instruments; rather, we seek to explore the error characteristics of broad classes of measurements. As such, instead of performing radiative transfer calculations to produce simulated IR and MW radiances, then running a synthetic water vapor retrieval (all of which should be specific to a particular instrument and spacecraft), we evaluate analogs to IR and MW retrieved water vapor fields by smoothing the WRF-simulated water vapor (mixing ratio) in the vertical using kernel functions that are close approximations to the weighting functions that would be produced in a retrieval.

We use IR kernels consistent with a high-spectralresolution sounder [Fig. 3a; e.g., the Atmospheric Infrared Sounder (AIRS)]. Kernels are derived by first calculating high-resolution radiance spectra and Jacobians for temperature and water vapor using the Line-by-Line Radiative Transfer Model (LBLRTM; e.g., Clough et al. 2005) using "midwave" wavelengths from 4.78-5.09- $\mu \mathrm{m}$ wavelengths, and assuming tropical profiles. Use of profiles representative of the tropics ensures we do not encounter problems in the mid- and upper troposphere in the lower latitude portions of our WRF domain (Fig. 1). An averaging kernel (see e.g., Rodgers 2000) is then constructed on the model layers, assuming a 625 -channel, $2 \times$ Nyquist-sampled grating spectrometer (with noise similar to AIRS in the midwave), and consistent with the retrieval methodology 
described in Irion et al. (2018). From these averaging kernels, vertical resolution is approximately $1.5 \mathrm{~km}$ for layers between the surface and $2.8-\mathrm{km}$ altitude, increasing linearly to $3.9 \mathrm{~km}$ at $7.8-\mathrm{km}$ altitude, with the resolution remaining at $3.9 \mathrm{~km}$ above this level. We use this vertical resolution to produce IR "smoothing kernels," which are unitless and represent the vertical smoothing effect associated with the use of an IR sounder.

The MW soothing functions are derived using the Liebe et al. (1993) absorption model and are consistent with microwave water vapor sounders that operate at frequencies between 150 and $183 \mathrm{GHz}$ (Fig. 3b; e.g., Brown et al. 2011). The weights, which have units of inverse kilometers, were generated using the U.S. Standard Atmosphere 1976 for temperature, and a surface water vapor specific humidity of $25 \mathrm{~g} \mathrm{~m}^{-3}$ with a scale height of $2 \mathrm{~km}$. For more information on the smoothing function derivation, the reader is referred to Bormann et al. (2013).

The smoothing functions in Fig. 3 are applied to the WRF water vapor fields over the entire model domain and at every output time interval. In reality, the position of the peak in the weighting function, as well as its width should depend on the vertical distribution of pressure, temperature, and water vapor. Our aim is to understand the effect of smoothing on the error characteristics of the simulated AMVs, and we expect that the results will not change substantially were we to use spatially varying smoothing functions. Finally, because we expect that infrared-based retrievals of water vapor will not be available below clouds, and microwave-based retrievals will not be available in raining regions, we apply the following masks to the IR- and MW-smoothed fields. To approximate cloud impacts on IR retrievals, any moisture field in a region with a ratio between upward longwave radiation at the top of the atmosphere and at the surface $<0.4$ is masked. This ratio was based on a visual comparison between the cloud fraction and the OLR ratio and is designed to mask clouds consistent with what is done in IR remote sensing retrievals (Irion et al. 2018). We note that this will primarily result in masking middle and high cloud, where there is sufficient difference between surface and top-of-atmosphere longwave radiation. We expect that, for low clouds, retrievals will be available above cloud top. Since we do not explicitly account for cloud-top height in our mask, our criterion likely leads to an underestimate of yield. For rain impacts on MW retrievals, a rain mask with precipitation rate $>3 \mathrm{~mm} \mathrm{~h}^{-1}$ is applied to the moisture fields. This threshold is consistent with the authors' experience with microwave remote sensing in the presence of clouds and precipitation.

The final output product from which AMVs are derived consists of mixing ratio fields on constant pressure surfaces. The number of vertical levels depends on the specifics of the observing system, as mentioned above in the description of the derivation of IR and MW smoothing kernels. Since we are tracking water vapor on constant pressure levels, rather than radiances (which may vary in their effective emission height based on the thermodynamic structure of the atmosphere), water vapor AMVs are not likely to suffer as greatly from the height assignment errors associated with tracking radiances. Rather, as we will demonstrate, the uncertainties derive from the characteristics of the water vapor field and its orientation with respect to the flow. In the results that follow, we focus our analysis primarily on AMVs at the 850-hPa level. While we expect both IR and MW sounders to also provide water vapor retrievals in the middle and upper free troposphere, the $850-\mathrm{hPa}$ water vapor and wind fields have a large dynamic range, allowing us to evaluate the performance of the tracking algorithm in a wide variety of conditions.

\section{AMV sensitivity to FOV and sampling rate, and state-dependent AMV errors}

We focus first on the characteristics of the AMV tracking algorithm and its sensitivity to FOV and sampling rate. As such, in the results presented in this section, we do not mask any features in cloudy or precipitating regions. Earlier studies have shown that the AMV yield (fraction of the targets for which AMVs may be successfully retrieved) and uncertainty (e.g., RMS vector difference) depends on the cost function aggregation region, which we are referring to as the target box (which is a function of sensor FOV; see section 2a above) and the time elapsed between tracking images. A longer time interval between images results in advection of features over greater distances, allowing more accurate wind estimation for a given feature tracking. However, the accuracy of feature tracking also depends upon the shapes of features remaining relatively coherent over the interval. At longer time intervals, rapidly evolving features (e.g., clouds) will register as noise rather than trackable features. However, we expect that the water vapor fields assessed in this study, especially those in cloud-free regions, will not experience as rapid changes as do clouds. Rapid evolution of water vapor structure is certainly possible in dynamic cloudy regions, which may be a factor for observations that can penetrate clouds (e.g., microwave sounders).

The selected size of the target box represents the desired scale of the features that are to be tracked between images. A larger box size benefits from sensitivity to larger-scale features/gradients that tend to evolve less rapidly. It also benefits from incorporating more FOVs, 
potentially increasing signal-to-noise ratio. However, a larger target box assumes that the wind speed and direction are approximately constant throughout, leading to potentially larger errors in regions of, for example, strong curvature in the flow. Selection of a larger target box also translates to a lower (coarser) effective resolution of retrieved AMVs assuming no overlap.

García-Pereda and Borde (2014) investigated a range of FOV and time interval combinations for cloud tracking as applied to Meteosat Second Generation (MSG)/SEVIRI geostationary $1 \mathrm{~km} \times 1 \mathrm{~km}$ VIS and $3 \mathrm{~km} \times 3 \mathrm{~km}$ IR imagery, and suggested a range of ideal scales on the basis of coverage and accuracy relative to rawinsonde verification. In our study, we revisit their analysis, focusing on features tracked in images of retrieved water vapor, valid in clear-sky (cloud free) conditions for infrared sounders and in nonprecipitating regions for microwave sounders. We test over a range of target box sizes whose lower bound is governed by the lowest number of pixels deemed sufficient for pattern matching $(13 \times 13$ pixels). (Note that the number of pixels necessary to track less nebulous, or static, features like terrain or coastlines is less.) For our simulated case, this yields a minimum target box size of $17 \mathrm{~km} \times 17 \mathrm{~km}$. We also test boxes that represent 2 times and 4 times this size in each linear direction, which correspond to boxes of $33 \mathrm{~km} \times 33 \mathrm{~km}$ and $65 \mathrm{~km} \times 65 \mathrm{~km}$, respectively. The reference 850 -hPa wind speeds and vectors from the WRF nature run are shown in Fig. 4c, the 850-hPa water vapor field is shown in Fig. 4d, and the winds returned by the tracking algorithm with successively greater box sizes are shown in Figs. 4e-g. It is clear that, as the target box size increases, the vector yield (Fig. 4a) increases from approximately $55 \%$ to nearly $90 \%$ while the rootmean-square vector difference (RMSVD; Fig. 4b) decreases from nearly 9 to just over $5 \mathrm{~m} \mathrm{~s}^{-1}$. The RMSVD is a commonly used measure of uncertainty in AMVs and is computed as

$$
\begin{aligned}
& \text { RMSVD } \\
& \qquad=\left\{\sum_{i=1}^{N}\left[\left(u_{\text {track }}-u_{\text {nature }}\right)^{2}+\left(v_{\text {track }}-v_{\text {nature }}\right)^{2}\right] / N\right\}^{1 / 2},
\end{aligned}
$$

where $u_{\text {nature }} / v_{\text {nature }}$ are the nature run wind, $u_{\text {track }} / v_{\text {track }}$ are the tracked wind, and $N$ is the number of data points.

Together, the desired minimum wind speed the algorithm is capable of tracking, and the water vapor field (or pixel) spatial resolution, determine the optimal elapsed time between successive water vapor images. This is because the AMV tracking algorithm requires more time for features to fully move across a coarser-resolution image, relative to one with higher resolution, for a given wind speed (Velden et al. 2005). For example, the pixel size in our highest resolution WRF domain is $1.33 \mathrm{~km}$. With a 5-min elapsed time between images, the minimum detectable wind speed will be $(1330 \mathrm{~m}) /(300 \mathrm{~s})=$ $4.43 \mathrm{~m} \mathrm{~s}^{-1}$. Allowing for longer elapsed time between images decreases the minimum detectable wind speed but may introduce additional uncertainty if features are not moving coherently (e.g., features are changing shape or there is curvature or acceleration in the flow). In addition, at very long time intervals, a significant portion of a feature may move entirely out of the search box leading to a failure of the algorithm to find a viable wind vector. We demonstrate the sensitivity to image frequency by varying the elapsed time between images in our highest resolution WRF domain from 5 to $20 \mathrm{~min}$ in 5-min intervals (Fig. 5). As the elapsed time interval lengthens, the AMV algorithm begins to have difficulty tracking some of the features in the target box, and the yield (Fig. 5a) decreases from $\sim 90 \%$ for a 5 -min interval to $\sim 70 \%$ for a 20 -min interval. At the same time, the RMSVD increases, likely because of curvature or acceleration in the flow causing ambiguity in the results.

We now explore how errors in the retrieved clear-air water vapor AMVs (as measured by wind speed differences between AMVs and the WRF nature run reference wind field) depend on the underlying state of the atmosphere. In particular, we look for the dependence of AMV error on wind speed and water vapor content (and the relationship between the two). We report our results in units of wind speed difference rather than RMSVD to provide a sense for the relative error when comparing true versus tracked wind speed. We track water vapor on the 850 -hPa pressure level and use an elapsed time of $10 \mathrm{~min}$ between images and a target box size of $65 \mathrm{~km} \times 65 \mathrm{~km}$, but note that the error structures are consistent across sampling intervals and box sizes. A comparison between the water vapor field and the AMVs in Figs. 4 and 5 shows that the tracking algorithm fails to produce an AMV where there is relatively low water vapor content. Plots of the wind speed difference as a function of water vapor mass mixing ratio (Fig. 6a) confirm this. The largest errors occur at very low water vapor content (less than $1 \mathrm{~g} \mathrm{~kg}^{-1}$ ), with the smallest error observed at water vapor values greater than $4 \mathrm{~g} \mathrm{~kg}^{-1}$, above which the wind speed difference is generally between $\pm 2 \mathrm{~m} \mathrm{~s}^{-1}$ and appears to be nearly unbiased. There is a functional dependence on wind speed as well (Fig. 6b), with larger errors found at increasingly greater wind speeds. In fact, there appear to be two regimes to the tracked wind error as a function of wind speed: one in which the wind speed error is relatively stable at approximately $\pm 2 \mathrm{~ms}^{-1}$, and another in which the wind 

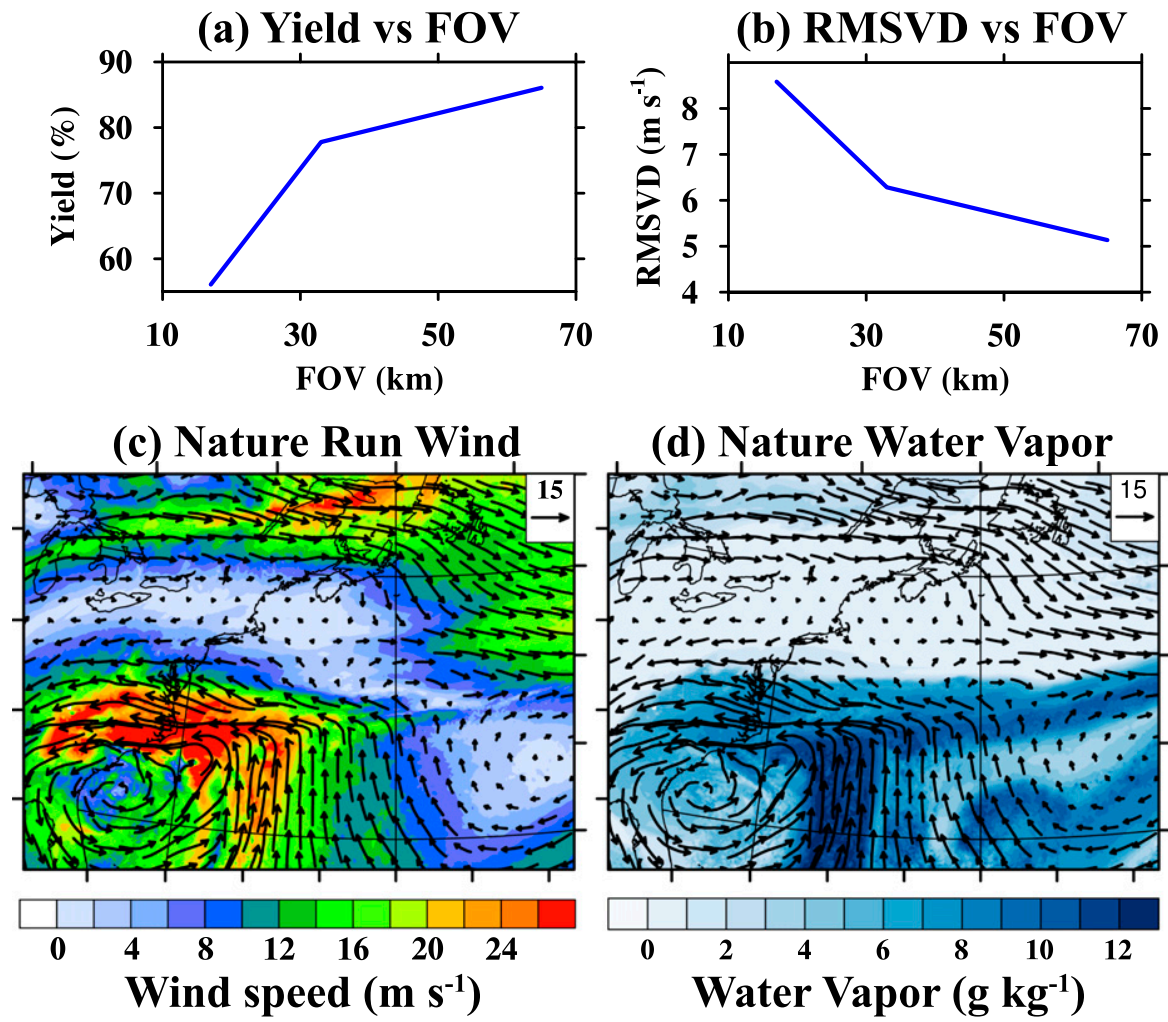

\section{(d) Nature Water Vapor}

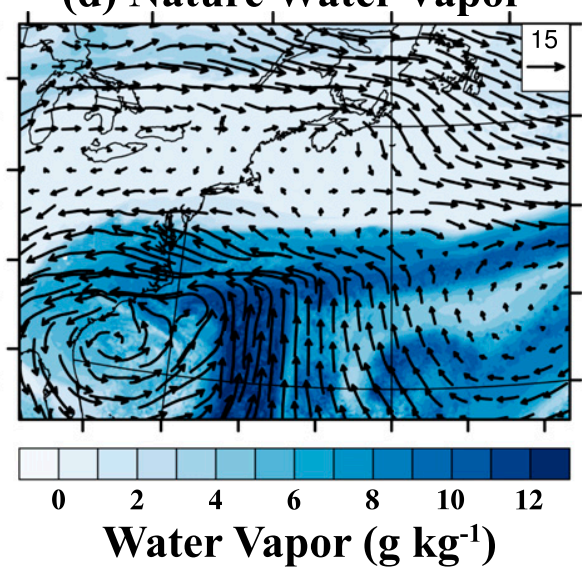

(e) FOV: 17 km
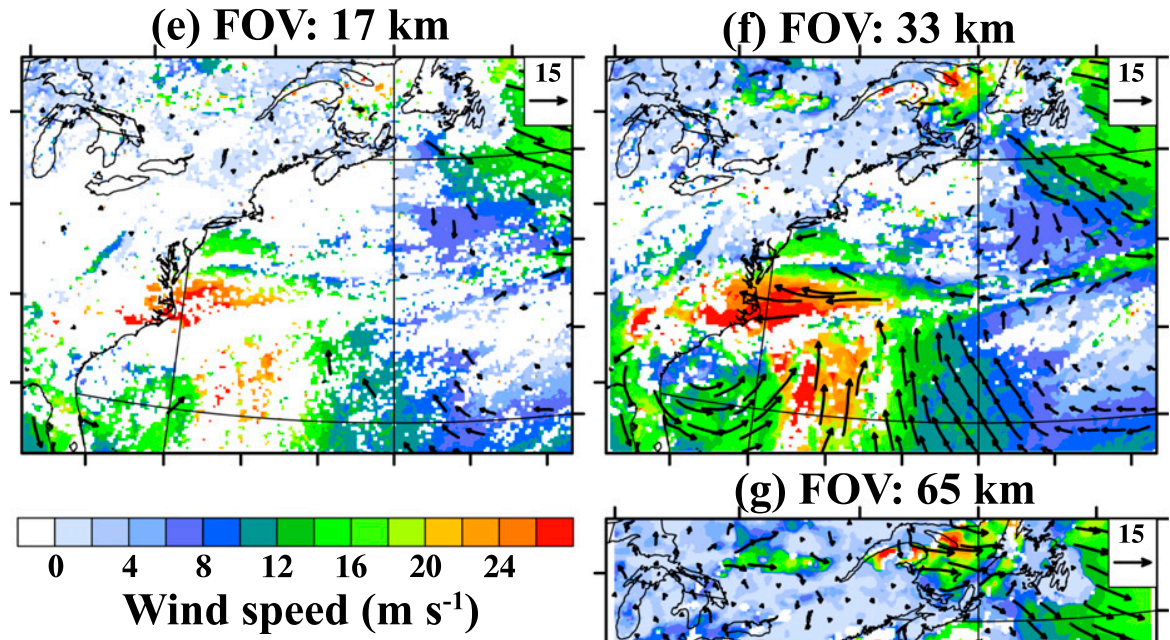

(g) FOV: $65 \mathrm{~km}$

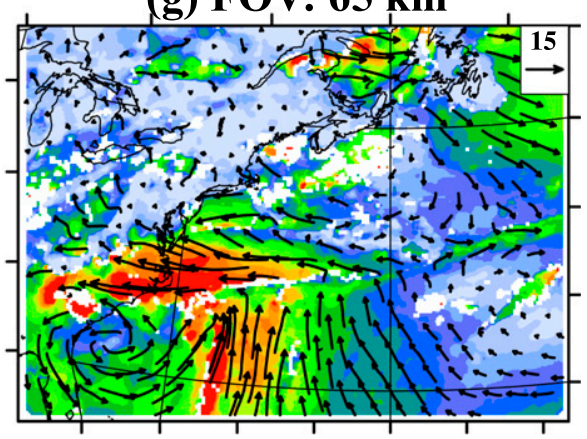

FIG. 4. Relationship between the field of view in the tracking algorithm vs (a) the percent of the footprints for which an AMV was successfully estimated (the yield) and (b) the root-mean-square vector difference (RMSVD). The WRF-modeled 850-hPa wind vectors overlaid on contour plots of $850-\mathrm{hPa}(\mathrm{c})$ wind speed and (d) water vapor mixing ratio. (e)-(g) The wind speed (color contours) and vectors obtained from the AMV tracking algorithm for successively larger fields of view. 
(a) Yield vs Sampling

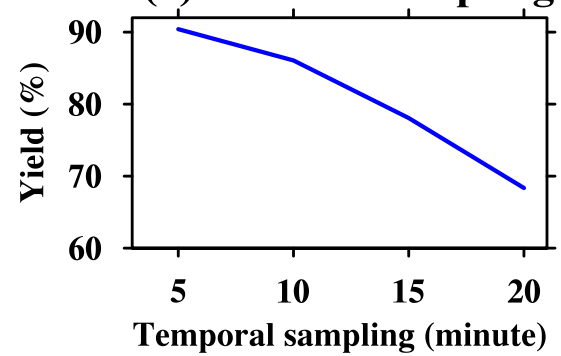

(c) Nature Run Wind

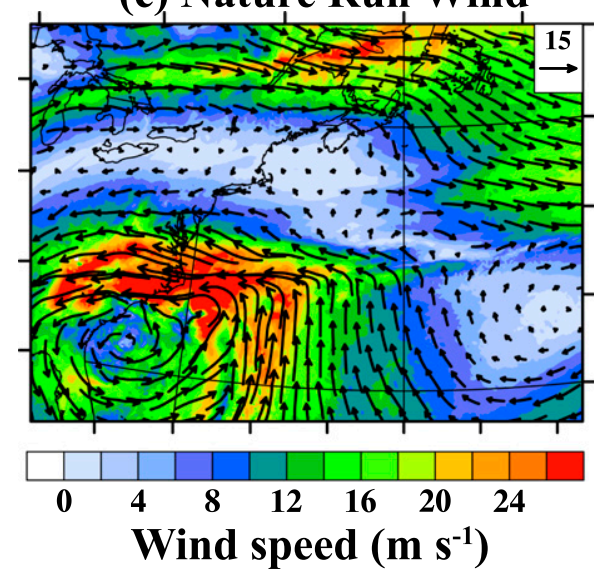

(e) 5 minutes

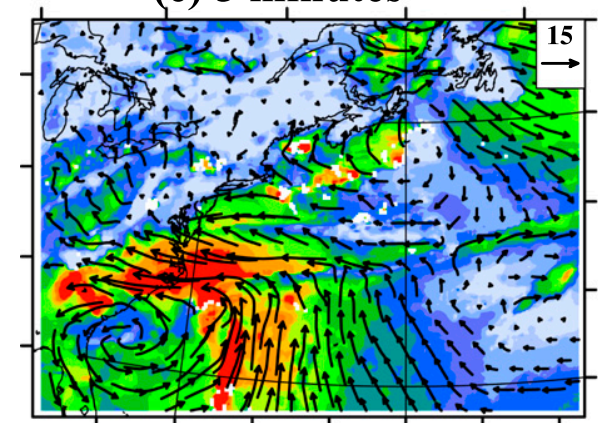

(g) 15 minutes

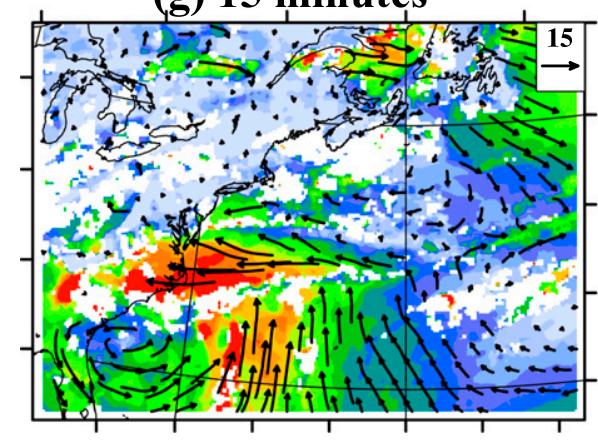

(b) RMSVD vs Sampling

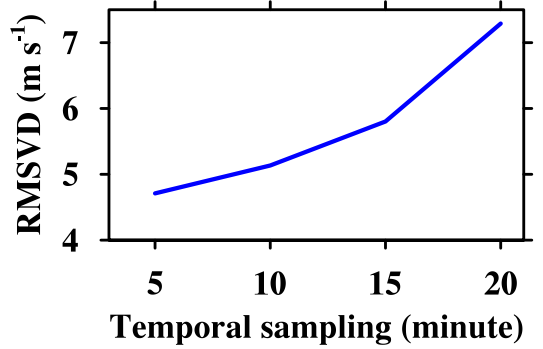

(d) Nature Water Vapor

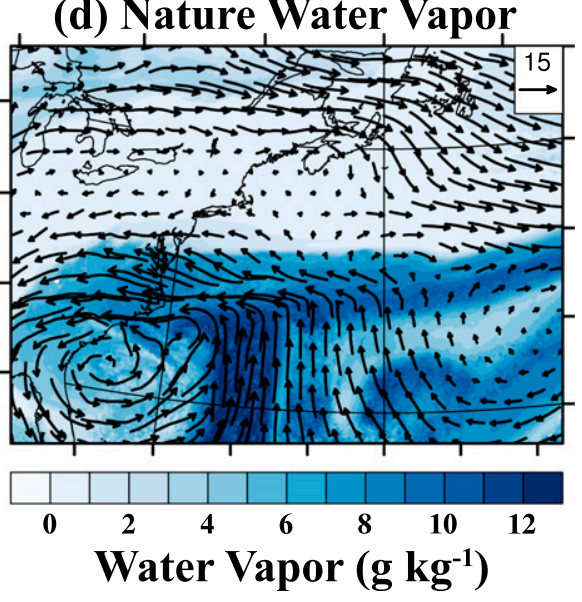

(f) 10 minutes

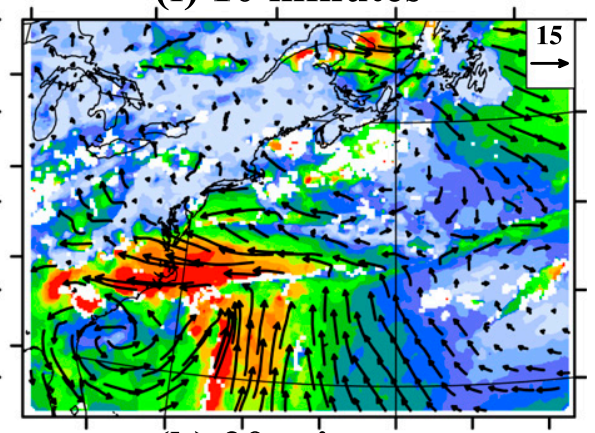

(h) 20 minutes

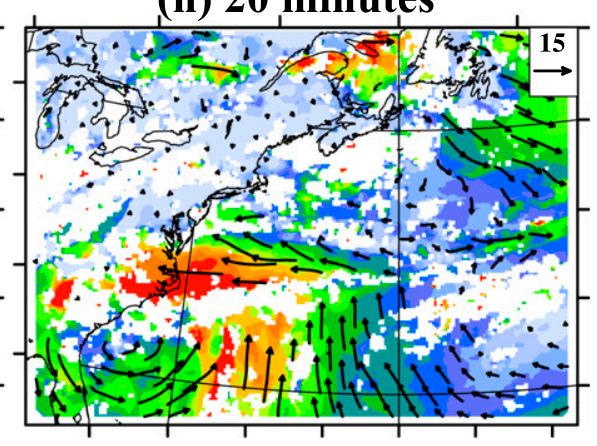

FIG. 5. Relationship between the elapsed time between water vapor fields used in the tracking algorithm vs (a) the percent of the footprints for which an AMV was successfully estimated (the yield) and (b) the RMSVD. The WRF-modeled 850-hPa wind vectors overlaid on contour plots of 850-hPa (c) wind speed and (d) water vapor mixing ratio. (e)-(h) The wind speed obtained from the AMV tracking algorithm for successively larger temporal sampling intervals. 

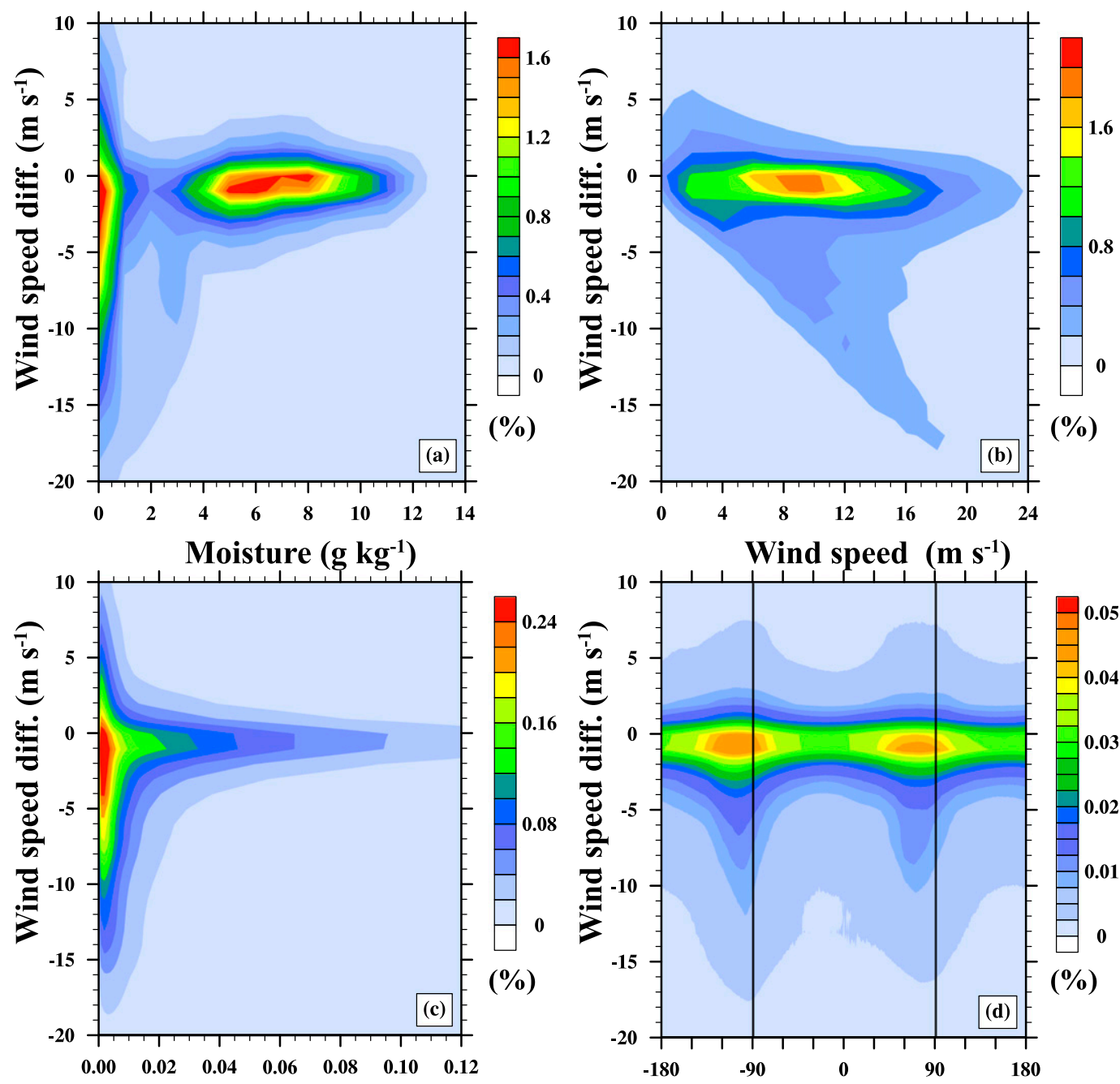

Moisture gradient $\left(\mathrm{g} \mathrm{kg}^{-1} \mathbf{k m}^{-1}\right)$

\section{Wind-moisture gradient angle (deg)}

FIG. 6. Difference between the tracked and true (WRF modeled) wind (tracked - true) at the 850-hPa pressure level as a function of (a) water vapor content, (b) wind speed, (c) water vapor gradient, and (d) the angle between the wind direction and the water vapor gradient. Color shading represents the percent of the total number of grid points that have a particular value of wind speed difference. Black vertical lines in (d) indicate the position of the $\pm 90^{\circ}$ angles.

speed error scales linearly with the wind speed. The larger values of error at wind speeds less than approximately $4 \mathrm{~m} \mathrm{~s}^{-1}$ are likely due to a lack of feature movement between images; features are not translating over sufficient distances during the elapsed time interval for the AMV algorithm to discern motion. Examination of the wind speed difference as a function of water vapor gradient (Fig. 6c) reveals that the gradient in water vapor also has a large influence on AMV error, with largest errors concentrated at the smallest gradients. This is expected, as the tracking algorithm requires contrast in an image to produce a traceable target and ultimately a successful AMV.
Last, we plot the AMV error as a function of the angle between the wind direction and the gradient in the water vapor field (Fig. 6d). In this case, angles of $\pm 90^{\circ}$ indicate that the wind is oriented parallel to water vapor isolines. In this situation, there may be no apparent difference between two successive images, resulting in retrieval of a lower (or even zero) wind speed when the winds were much stronger in reality. This is borne out in the plot of wind speed difference versus the angle between the wind and the water vapor gradient. The largest errors (wind speed differences $>10 \mathrm{~m} \mathrm{~s}^{-1}$ ) occur for wind-gradient angles of $\pm 90^{\circ}$. Examination of the contours of frequency indicates that it is more common for winds to be oriented 
(a) Nature Run
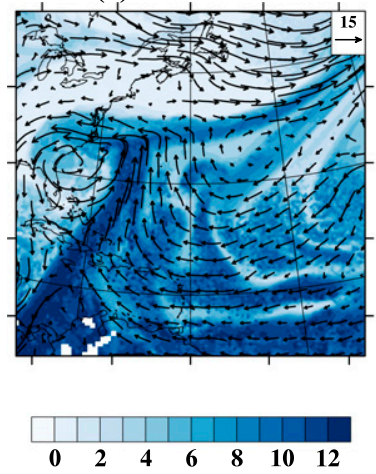

Water Vapor $\left(\mathrm{g} \mathrm{kg}^{-1}\right)$ (b) IR Smoothed

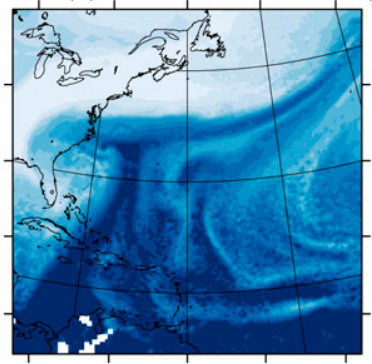

(e) MW Smoothed

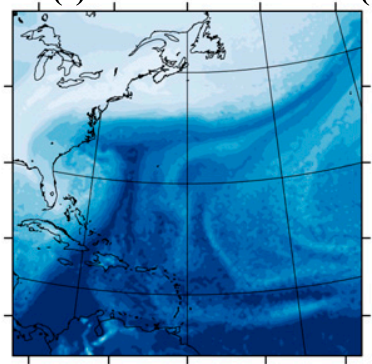

(c) IR Smoothed, Cloud Mask

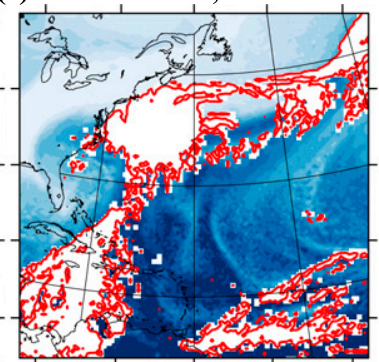

(f) MW Smoothed, Rain Mask

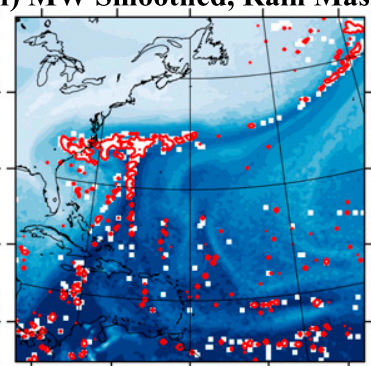

(d) Nature Run - IR

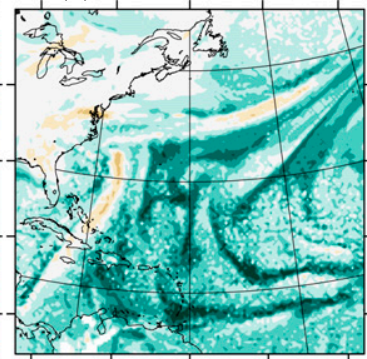

(g) Nature Run - MW

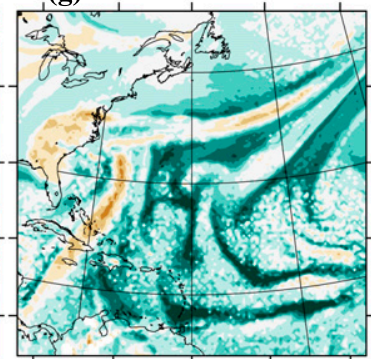

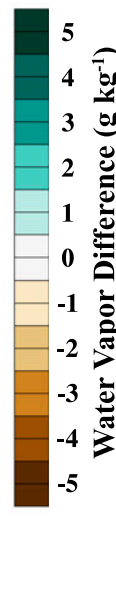

FIG. 7. Water vapor content on WRF domain d02 at the 850-hPa level from (a) the unsmoothed simulation, water vapor smoothed using IR kernels (b) without and (c) with a cloud mask, and water vapor smoothed using microwave kernels (e) without and (f) with a rain mask. Also shown is the difference in water vapor between the nature run and the (d) IR-smoothed and (g) MW-smoothed fields. The red contours and white regions in (c) and (f) correspond to the boundaries of regions that meet the criterion for the IR and MW mask, respectively. See the text for details on the cloud and rain masks and Fig. 3 for a depiction of the smoothing kernels.

at angles of approximately $\pm 90^{\circ}$ to the water vapor gradient. We suspect that this is due to dynamic/thermodynamic balance constraints. Winds in the latitudes spanned by the WRF domain are in approximately geostrophic balance. As such, the wind is generally oriented parallel to geopotential height contours. In geostrophic balance, to first order, the mass and temperature fields on a pressure surface are directly related. Since the Clausius-Clapeyron relationship between equilibrium vapor pressure and temperature places a strong constraint on water vapor content, there is a general relationship between water vapor concentration and temperature at a given pressure level. The result is a general tendency for the wind to be oriented parallel to isolines of water vapor, and therefore perpendicular to its gradient. The approximately $10^{\circ}$ shift in the location of the maximum number of data points (from $\pm 90^{\circ}$ to $+80^{\circ} \%-100^{\circ}$ ) is due to friction effects on the geostrophic wind. We have verified this by analyzing water vapor gradient versus wind in the upper troposphere where no such shift is evident (not shown).

Note that, where the AMV wind speed differs from the true wind speed, the differences are predominantly negative (tracked winds are less than true winds). This negative bias, with a similar magnitude, is also observed when comparing AMVs to radiosondes. Bresky et al. (2012) identified two primary reasons related to the algorithm for a slow bias: 1) assigning the AMV height too low in the atmosphere and 2) tracking with a large target box. Since, we are tracking features on model pressure levels, the height assignment is inherent in the data. Therefore, the size of the target may contribute to the slow bias, as a large target window has the tendency to smooth the instantaneous wind field. On the other hand, the tracked wind speed is greater than the true wind primarily at low true wind speeds (Fig. 6b) and may be due to the emergence of features associated with processes other than horizontal advection (e.g., vertical motion or cloud processes).

We now examine the effect of vertical smoothing of the water vapor fields on tracked winds. We utilize the 4-km grid spacing WRF domain for this analysis to allow for a larger domain and greater variety in the winds and water vapor content. Figure 7 depicts the water vapor on d02 for the nature run (Fig. 7a), as well as water vapor smoothed using IR (Fig. 7b) and MW (Fig. 7e) averaging functions. We note that IR sounders are not able to produce water vapor retrievals below clouds, and MW sounders are limited to regions without heavy precipitation. Figures $7 \mathrm{c}$ and $7 \mathrm{f}$ depict the smoothed water vapor fields masked to exclude cloudy and raining regions, respectively. For reference, the difference in water vapor mixing ratio introduced by smoothing vertically using IR and MW averaging functions is shown in Figs. $7 \mathrm{~d}$ and $7 \mathrm{~g}$, respectively. It is clear from Figs. 3 and 7 that the IR weighting functions are more sharply peaked 
(a) Nature Run

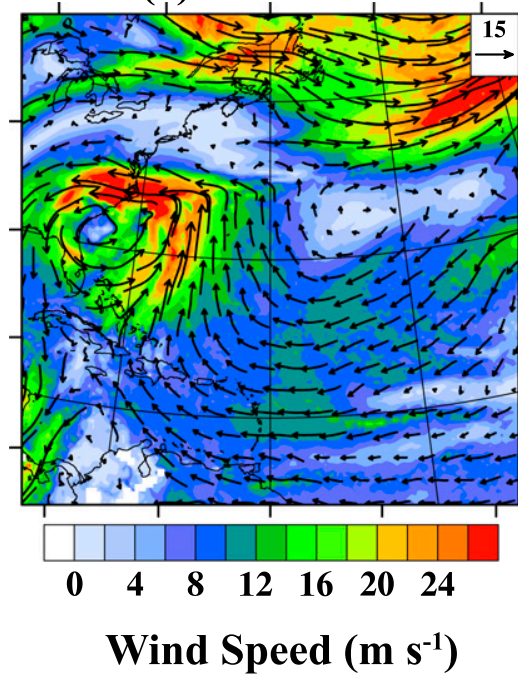

FIG. 8. Wind speed and vectors at the $850-\mathrm{hPa}$ level from (a) the full WRF Model output, tracked from water vapor fields smoothed with IR kernels (b) without and (c) with the cloud mask or smoothed with microwave kernels (d) without and (e) with the rain mask. (b) IR Smoothed

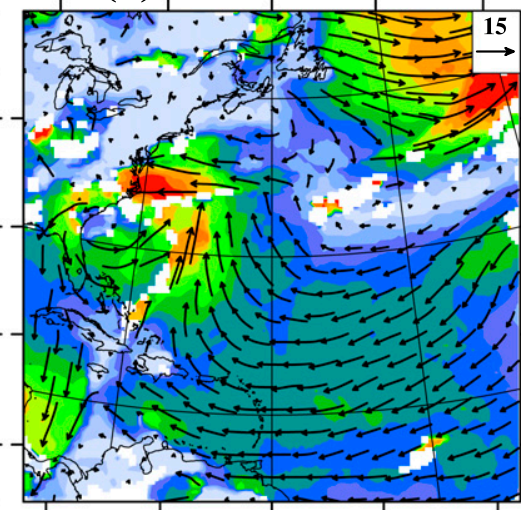

(d) MW Smoothed

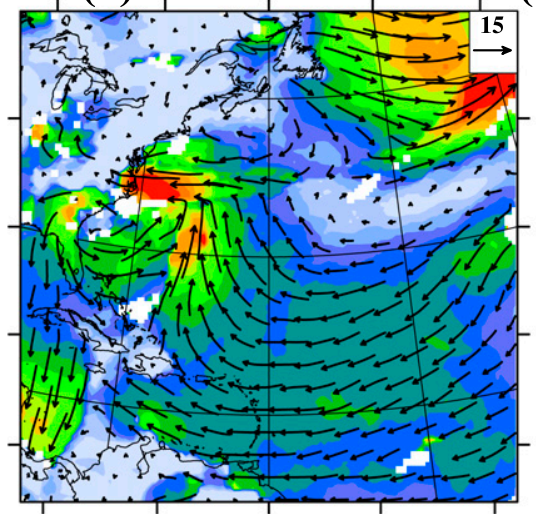

(c) IR Smoothed, Cloud Mask

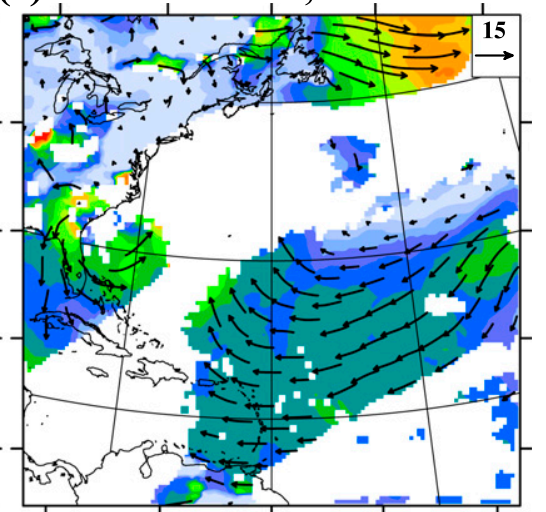

(e) MW Smoothed, Rain Mask

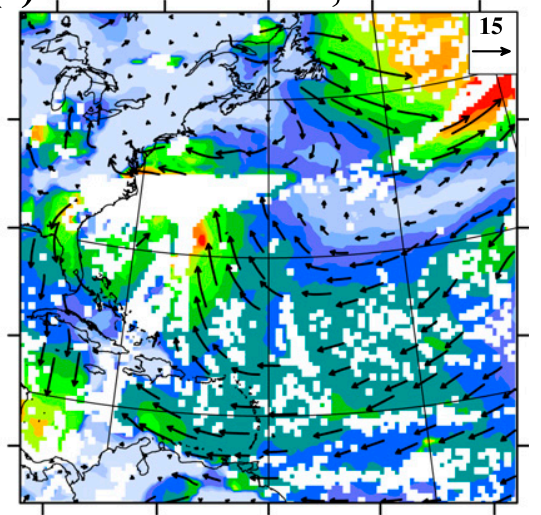

in the lower troposphere, and that this results in a smaller degree of smoothing in the water vapor fields, and consequently smaller differences in water vapor (as compared with the nature run) for IR than for MW. However, MW sounders operate in cloudy conditions, resulting in smaller loss of signal relative to IR. Comparison between the AMVs tracked from the nature run versus those tracked from IR-smoothed and MWsmoothed fields is depicted in Fig. 8. Figures $8 \mathrm{~b}$ and $8 \mathrm{~d}$ show that the IR-smoothed fields more closely approximate the nature run winds than do the MW winds, but there are larger gaps in the IR winds relative to MW. Note that the masked regions in Figs. $8 \mathrm{~b}$ and $8 \mathrm{~d}$ appear larger than those in Figs. $7 \mathrm{c}$ and $7 \mathrm{f}$ because the mask is applied to the $33 \mathrm{~km} \times 33 \mathrm{~km}$ FOVs in the tracked data. Recalling that tracking can fail where the cost function has no robust minima, we can identify the effect of clouds and raining regions on yield in Fig. 9, where it can be seen that the smoothing itself does not significantly affect yield (Fig. 9a) or RMSVD (Fig. 9b). However, IR sounders not being able to retrieve lower tropospheric water vapor in cloudy conditions significantly affects both the yield and the RMSVD. The larger RMSVD in the IR-smoothed and cloud-masked AMVs is likely due to RMSVDs being relatively lower in regions with large water vapor content (Fig. 4a), and many of the regions containing the largest water vapor contents are also regions with clouds.

The case we have chosen for analysis has a large range of wind speeds and directions, water vapor contents, and water vapor gradient values. As such, it is representative of a wide range of conditions. To determine whether the state-dependent errors we find in the WRF output are representative of global wind speed and water vapor content, we conduct an experiment in which we track water vapor output from the NASA Global Modeling and Assimilation Office (GMAO) G5NR (Putman et al. 2014). The G5NR consists of a 2-yr free-running global atmosphere-only simulation run at $7-\mathrm{km}$ (mesoscale resolving) grid spacing. The larger grid spacing in the G5NR necessitates a longer temporal interval between water vapor images, and we have chosen to use a $60-\mathrm{min}$ time separation because it has been determined in our tests (not shown) to produce the smallest uncertainties. State-dependent error analysis analogous to that conducted for the WRF fields is shown for the G5NR AMVs in Fig. 10. Comparison between Figs. 6 and 10 indicates that the same general conclusions hold: Retrieved clearair water vapor AMV error is a systematic function of the water vapor content, wind speed, and water vapor 

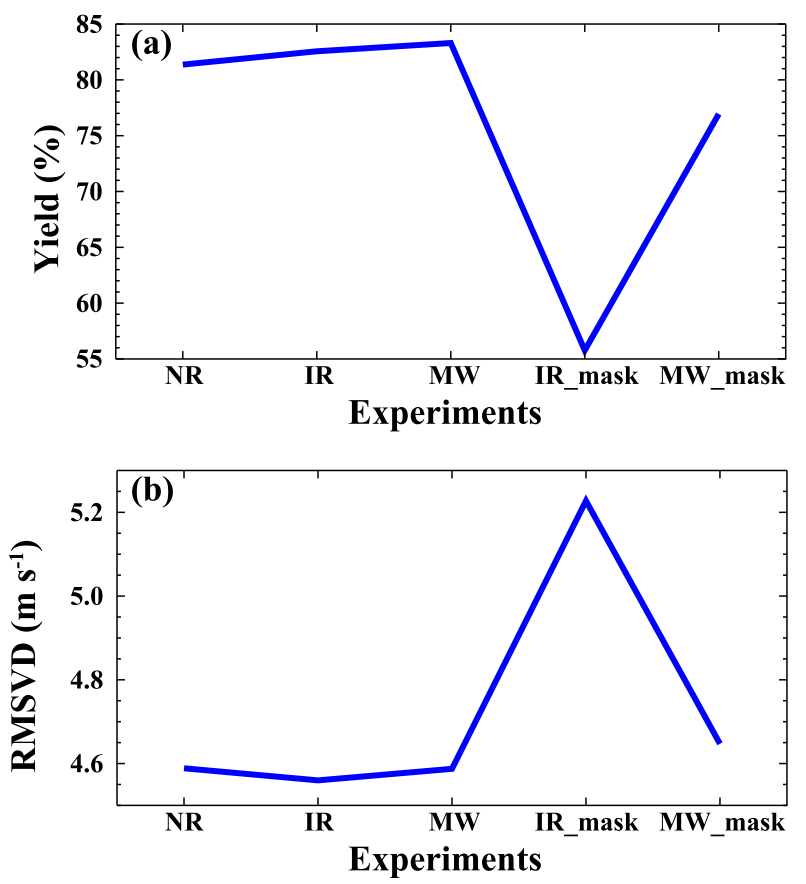

FIG. 9. (a) Yield (fraction of the footprints where the AMV tracking was successful) and (b) RMSVD for winds tracked from the unsmoothed WRF-modeled water vapor (NR) and for winds tracked from water vapor smoothed with IR or MW kernels, with and without cloud and rain mask.

gradient (errors decrease with increasing values of all of these quantities). As in the higher-resolution WRF simulation results, errors are largest where the wind direction runs perpendicular to the water vapor gradient (Fig. 10d). In contrast to the WRF data (Fig. 6d), the largest concentrations of points in the GEOS-5 are centered on the $\pm 90^{\circ}$ angles, and a smaller proportion of winds are oriented $\pm 90^{\circ}$ to the water vapor gradient. This reflects the fact that the results in Fig. 10 are computed over a global domain; the tropics are not in geostrophic balance, and friction induced departures from geostrophy in midlatitudes will have the opposite sign in the Northern versus Southern Hemisphere. We note that the error structures are somewhat smoother for the GEOS5 data as compared with the WRF data, and we suspect this is due to a combination of coarser horizontal resolution, longer tracking interval, and inclusion of more data.

As a final comparison, we compute the statedependent errors in the midtroposphere, where water vapor content is lower but, over much of the globe, the wind speeds are higher (Fig. 11). Comparison of Figs. 10 and 11 indicate that the error structures for the two levels are very similar. Water vapor and water vapor gradient values are smaller at $500 \mathrm{hPa}$ than at $850 \mathrm{hPa}$, yet a comparison between Figs. 10 and 11 shows that the retrieved clear-air water vapor AMV errors are smaller at relatively low values of water vapor and water vapor gradient at $500 \mathrm{hPa}$ (Figs. 11a,c) than they are at $850 \mathrm{hPa}$ (Figs. 10a,c), likely because a greater proportion of the temporal changes in water vapor features are due to horizontal advection. The errors as a function of wind speed and angle between wind and water vapor gradient (Figs. 11b,d) are also very similar at 500 and $850 \mathrm{hPa}$.

\section{Discussion}

To our knowledge, this is the first study to systematically explore the state dependence of uncertainties in retrieved clear-air water vapor AMVs. The results have implications for the potential use of such AMVs in numerical weather prediction data assimilation systems and in forecast observing system simulation experiments. It is typical in a data assimilation analyses to assume that errors in AMVs are independent of time and location. Our results indicate that this is not the case, and that ignoring the state dependence of AMV uncertainties may lead to data being either under- or overutilized in the initial analysis. We are in the process of deriving a function from our analysis that can be used to assign an uncertainty estimate to AMVs based on the first guess (background, a priori) wind and water vapor fields. We will report on the derivation of this error function, and the effect of the use of state-dependent uncertainties in forecast analyses and OSSEs in a future paper.

Before we close, we wish to emphasize that there are other sources of uncertainty that we did not explore in this set of experiments. In the real world, water vapor retrieved from IR and MW sounders will not only be smoothed in the vertical but may also contain noise. Noisy images are intrinsically more difficult to track, and errors in real AMVs will likely be larger than those we report here. In addition, the AMV tracking algorithm itself will be a factor in the uncertainty of the derived winds. We have chosen to use a well-tested but also relatively simple AMV algorithm. Recent work has demonstrated that tracking algorithms based on optical flow (Bresky and Daniels 2006; Wu et al. 2016) and neural network techniques (F. He 2019, personal communication) may produce higher yield and lower uncertainties than the algorithm we used in our experiments. Comparison among wind tracking algorithms is beyond the scope of this paper.

\section{Summary and conclusions}

This study has used output from two simulations, a highresolution regional (WRF) simulation of an extratropical 

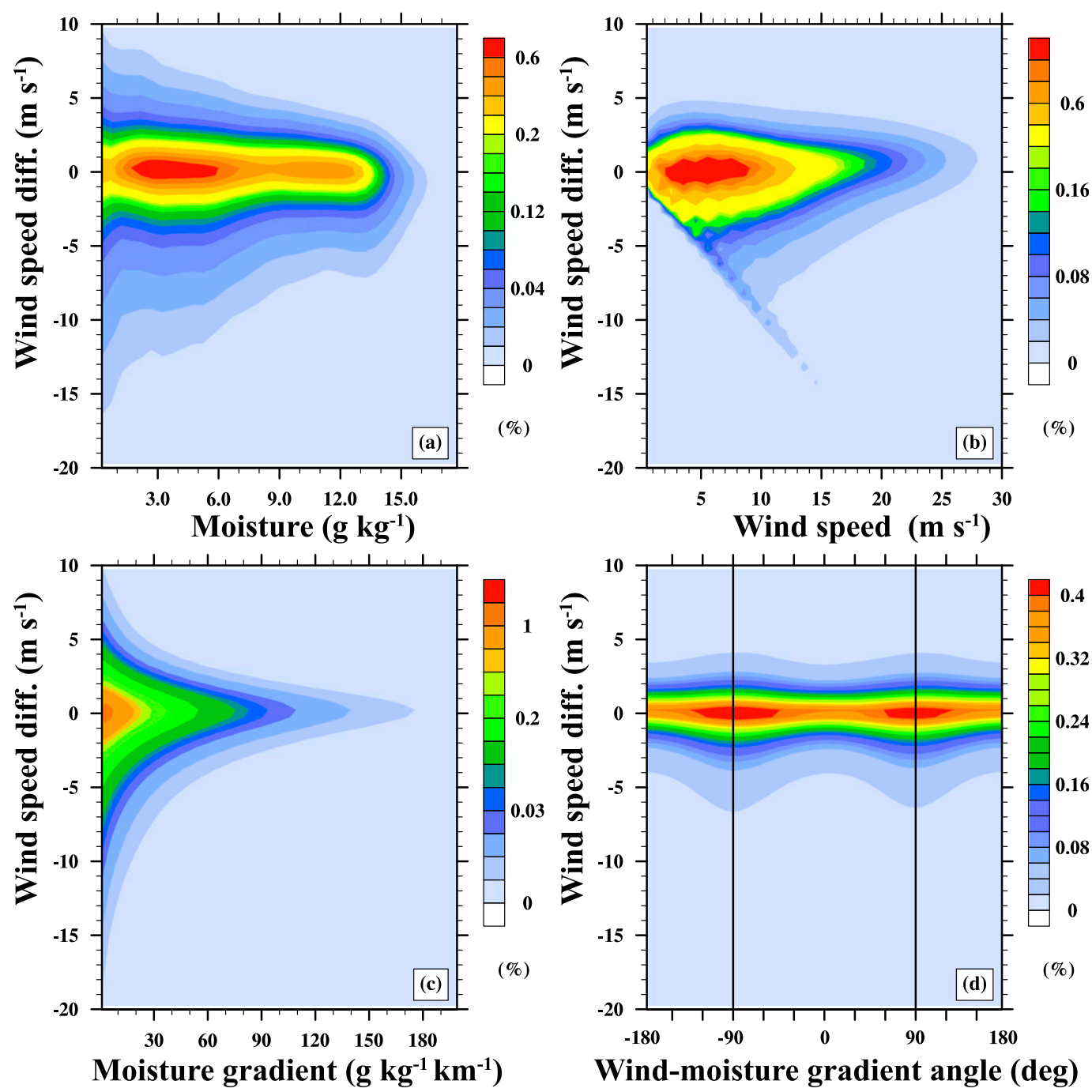

FIG. 10. As in Fig. 6, but for state-dependent wind speed differences computed from the global G5NR.

cyclone using WRF and a global mesoscale-resolving simulation using the NASA GEOS-5 model, to study the error characteristics of atmospheric motion vectors produced via application of a feature tracking algorithm to retrieved (height resolved) clear-air water vapor fields. We explored the sensitivity of the AMV uncertainty and yield to changes in sampling time interval and target box size (related to spatial field of view), and also explored the effect of smoothing the water vapor in the vertical consistent with retrievals from infrared and microwave sounding instruments.

The major conclusions of our study are the following as pertains to retrieved clear-air water vapor AMVs:

1) Increasing the target box size for the feature tracking algorithm increases the yield (decreases the number of failed retrievals) and decreases the RMSVD between tracked and model reference (true) winds.
However, the resulting AMVs have a lower effective horizontal resolution.

2) When AMVs are obtained from high-spatialresolution fields, increasing the time interval between images decreases the yield and increases the RMSVD, and the decreases in yield are primarily in regions of stronger curvature or acceleration in the flow.

3) Uncertainties in these AMVs are highly state dependent and are largest for regions with small water vapor content and small water vapor spatial gradient, as well as for regions in which contours of water vapor content isolines run parallel to the flow.

4) Application of vertical smoothing functions consistent with what may be expected from retrievals of water vapor from infrared and microwave sounders results in virtually no change in yield or error; however, the yield from IR sounders is much lower 

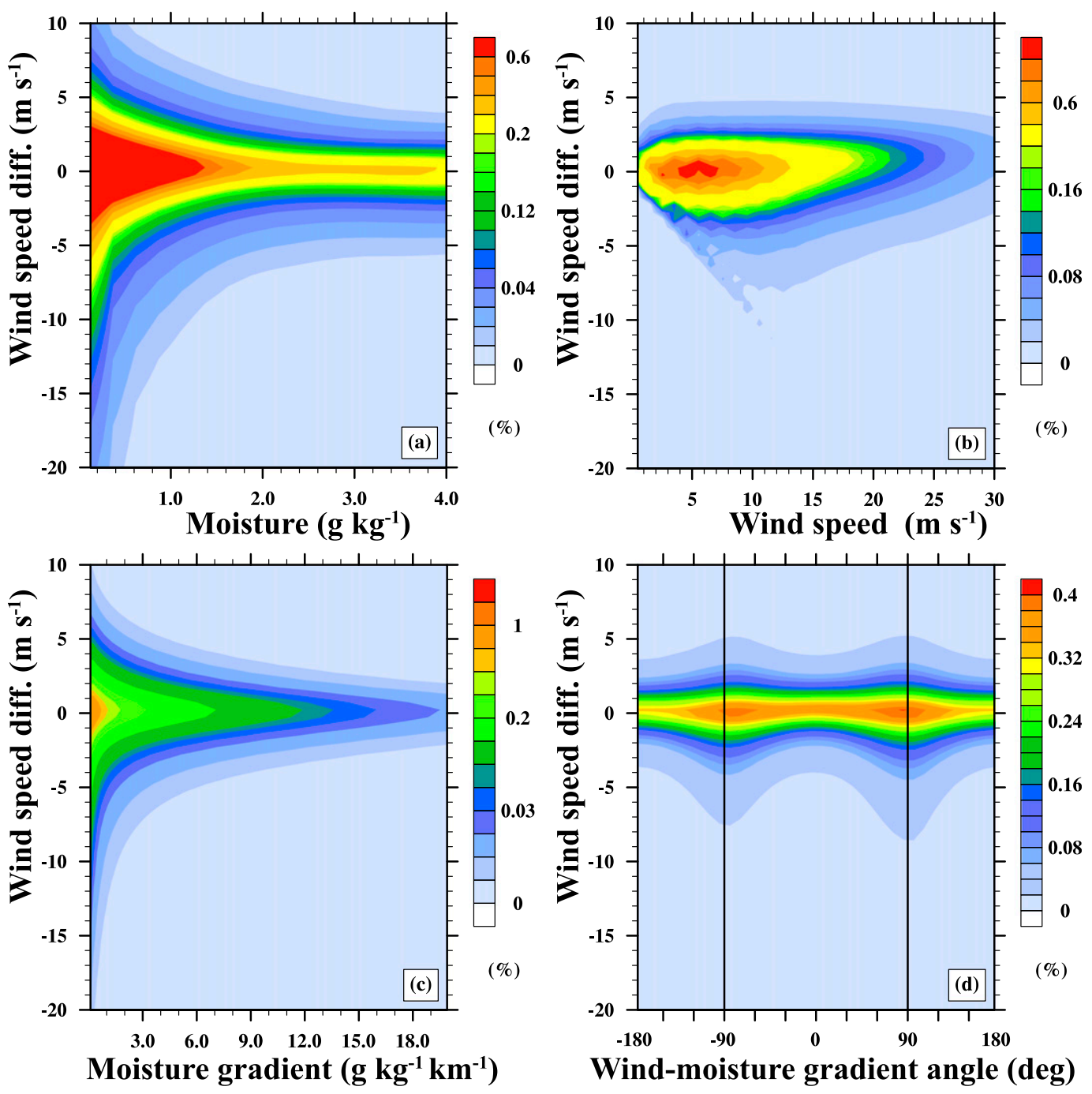

FIG. 11. As in Fig. 6, but for state-dependent tracked - GEOS-5 wind speed differences computed at the 500-hPa pressure level.

than for MW sounders due to the inability to retrieve water vapor in cloudy regions from IR sounders.

5) These AMVs have the same state-dependent uncertainty structures in a coarser-resolution global simulation as they do in the regional high-resolution simulation. The error structures are similar in both the lower troposphere and midtroposphere, even though midtropospheric water vapor contents are smaller.

The results we have obtained have implications both for the design of observing systems, and for data assimilation. An observing system designed to measure height-resolved winds may include a passive component that obtains information on wind from water vapor feature tracking. If sequences of images are obtained from a train of low-Earth-orbiting satellites, a critical design question will be the spacing between spacecrafts. Our results indicate that uncertainties in water vapor AMVs depend on the time elapsed between images. In the case of a geostationary platform, there will still need to be decisions as to the optimal elapsed time between images to maximize the information in the retrieved wind field.

In any data assimilation system, the impact of an observation depends on how the measurement uncertainty is specified. The large impact of height assignment errors for spacecraft with small numbers of water vapor channels has limited the impact of clear-air AMVs in data assimilation at operational centers. It is possible that AMVs derived from MW or IR sounders with improved height specification could have a much greater impact in a DA system. In addition, if the uncertainty 
used in the DA system is smaller than it is in reality, then the observations may have a detrimental impact on the analysis and subsequent forecast (erroneous observations will be given too much weight). Conversely, if the specified measurement uncertainty is larger than it is in reality, then observations will be given too little weight in the DA system. Our results indicate that specification of a constant uncertainty (invariant in time and space) is an oversimplification, and that in fact the uncertainty is state dependent. We are currently conducting tests to ascertain the effect of using state-dependent measurement errors in a water vapor AMV forecast OSSE.

Acknowledgments. This work was supported by NASA's The Science of TERRA, AQUA, and SUOMI NPP program Grant NNH17ZDA001N-TASNPP. A portion of this research was carried out at the Jet Propulsion Laboratory, California Institute of Technology, under a contract with the National Aeronautics and Space Administration. All rights reserved.

\section{REFERENCES}

Berger, H., R. Langland, C. S. Velden, C. A. Reynolds, and P. M. Pauley, 2011: Impact of enhanced satellite-derived atmospheric motion vector observations on numerical tropical cyclone track forecasts in the western North Pacific during TPARC/TCS-08. J. Appl. Meteor. Climatol., 50, 2309-2318, https://doi.org/10.1175/JAMC-D-11-019.1.

Bormann, N., A. Fouilloux, and W. Bell, 2013: Evaluation and assimilation of ATMS data in the ECMWF system. J. Geophys. Res., 118, $12970-12$ 980, https://doi.org/10.1002/ 2013JD020325.

Bresky, W., and J. Daniels, 2006: The feasibility of an optical flow algorithm for estimating atmospheric motion. Proc. Eighth Int. Winds Workshop, Beijing, China, EUMETSAT, P47_S4_04, http://www.eumetsat.int/website/wcm/idc/idcplg?IdcService= GET_FILE\&dDocName=PDF_CONF_P47_S4_04_DANIELS_ $\mathrm{V} \&$ RevisionSelectionMethod $=$ LatestReleased\&Rendition $=$ Web.

, — A. A. Bailey, and S. T. Wanzong, 2012: New methods toward minimizing the slow speed bias associated with atmospheric motion vectors. J. Appl. Meteor. Climatol., 51, 21372151, https://doi.org/10.1175/JAMC-D-11-0234.1.

Brown, S. T., B. Lambrigtsen, R. F. Denning, T. Gaier, P. Kangaslahti, B. H. Lim, J. M. Tanabe, and A. B. Tanner, 2011: The High-Altitude MMIC Sounding Radiometer for the Global Hawk unmanned aerial vehicle: Instrument description and performance. IEEE Trans. Geosci. Remote Sens., 49, 3291-3301, https://doi.org/10.1109/ TGRS.2011.2125973.

Clough, S. A., M. W. Shephard, E. J. Mlawer, J. S. Delamere, M. J. Iacono, K. Cady-Pereira, S. Boukabara, and P. D. Brown, 2005: Atmospheric radiative transfer modeling: A summary of the AER codes. J. Quant. Spectrosc. Radiat. Transfer, 91, 233244, https://doi.org/10.1016/j.jqsrt.2004.05.058.

Crespo, J. A., and D. J. Posselt, 2016: A-Train based case study of stratiform-convective transition within a warm conveyor belt. Mon. Wea. Rev., 144, 2069-2084, https://doi.org/10.1175/ MWR-D-15-0435.1.

Dee, D. P., and Coauthors, 2011: The ERA-Interim reanalysis: Configuration and performance of the data assimilation system. Quart. J. Roy. Meteor. Soc., 137, 553-597, https://doi.org/ 10.1002/qj.828.

Eigenwillig, N., and H. Fischer, 1982: Determination of midtropospheric wind vectors by tracking pure water vapor structure in METEOSAT water vapor image sequences. Bull. Amer. Meteor. Soc., 63, 44-57, https://doi.org/10.1175/ 1520-0477-63.1.29.

García-Pereda, J., and R. Borde, 2014: The impact of the tracer size and the temporal gap between images in the extraction of atmospheric motion vectors. J. Atmos. Oceanic Technol., 31, 1761-1770, https://doi.org/10.1175/JTECH-D-13-00235.1.

Gentry, B., and Coauthors, 2008: Recent US activities toward development of a global tropospheric 3D wind profiling system. 2008 Fall Meeting, San Francisco, CA, Amer. Geophys. Union, Abstract A21F-0253.

Grell, G. A., and S. R. Freitas, 2014: A scale and aerosol aware stochastic convective parameterization for weather and air quality modeling. Atmos. Chem. Phys., 14, 5233-5250, https:// doi.org/10.5194/acp-14-5233-2014.

Holmlund, K., 1993: Operational water vapor wind vectors from Meteosat imagery. Proc. Second Workshop on Wind Extraction from Operational Satellite Data, Tokyo, Japan, EUMETSAT, 77-84. [Available from EUMETSAT Publications, Am Kavalleriesand 31, D-64295 Darmstadt, Germany.]

Hong, S.-Y., and J. J. Lim, 2006: The WRF single-moment microphysics scheme (WSM6). J. Korean Meteor. Soc., 42, 129-151.

Iacono, M. J., J. S. Delamere, E. J. Mlawer, M. W. Shephard, S. A. Clough, and W. D. Collins, 2008: Radiative forcing by longlived greenhouse gases: Calculations with the AER radiative transfer models. J. Geophys. Res., 113, D13103, https://doi.org/ 10.1029/2008JD009944.

Irion, F. W., and Coauthors, 2018: Single-footprint retrievals of temperature, water vapor and cloud properties from AIRS. Atmos. Meas. Tech., 11, 971-995, https://doi.org/10.5194/ amt-11-971-2018.

Janjić, Z. I., 1994: The step-mountain eta coordinate model: Further developments of the convection, viscous sublayer and turbulence closure schemes. Mon. Wea. Rev., 122, 927-945, https://doi.org/10.1175/1520-0493(1994)122<0927: TSMECM $>2.0 . \mathrm{CO} ; 2$.

Key, J., D. Santek, C. S. Velden, N. Bormann, J.-N. Thepaut, L. P. Riishojgaard, Y. Zhu, and W. P. Menzel, 2003: Cloud-drift and water vapor winds in the polar regions from MODIS. IEEE Trans. Geosci. Remote Sens., 41, 482-492, https://doi.org/ 10.1109/TGRS.2002.808238.

Lambrigtsen, B., H. V. Dang, F. J. Turk, S. M. Hristova-Veleva, H. Su, and Y. Wen, 2018: All-weather tropospheric 3-D wind from microwave sounders. IEEE J. Sel. Top. Appl. Earth Obs. Remote Sens., 11, 1949-1956, https://doi.org/10.1109/ JSTARS.2018.2814540.

Le Marshall, J. F., N. Pescod, R. Seaman, G. Mills, and P. Stewart, 1994: An operational system for generating cloud drift winds in the Australian region and their impact on numerical weather prediction. Wea. Forecasting, 9, 361-370, https://doi.org/10.1175/ 1520-0434(1994)009<0361:AOSFGC >2.0.CO;2.

Liebe, H. J., G. A. Hufford, and M. G. Cotton, 1993: Propagation modeling of moist air and suspended water/ice particles at frequencies below $1000 \mathrm{GHz}$. Atmospheric Propagation Effects through Natural and Man-Made Obscurants for Visible to 
MM-Wave Radiation, Neuilly-sur-Seine, France, AGARD, 3, https://apps.dtic.mil/dtic/tr/fulltext/u2/a276919.pdf.

Loeb, N. G., and Coauthors, 2018: Clouds and the Earth's Radiant Energy System (CERES) Energy Balanced and Filled (EBAF) Top-of-Atmosphere (TOA) Edition 4.0 data product. J. Climate, 31, 895-918, https://doi.org/10.1175/JCLI-D-17-0208.1.

Menzel, W. P., 2001: Cloud tracking with satellite imagery: From the pioneering work of Ted Fujita to the present. Bull. Amer. Meteor. Soc., 82,33-47, https://doi.org/10.1175/ 1520-0477(2001)082<0033:CTWSIF > 2.3.CO;2.

- W. L. Smith, and T. R. Stewart, 1983: Improved cloud motion wind vector and altitude height assignment using VAS J. Climate Appl. Meteor., 22, 377-384, https://doi.org/10.1175/ 1520-0450(1983)022<0377:ICMWVA >2.0.CO;2.

Mueller, K. J., C. Moroney, V. Jovanovic, M. J. Garay, J. P. Muller, L. Di Girolamo, and R. Davies, 2013: MISR level 2 cloud product algorithm theoretical basis. JPL Tech. Doc. D-73327, 51 pp., http://eospso.nasa.gov/sites/default/files/ atbd/MISR_L2_CLOUD_ATBD-1.pdf.

National Academies of Sciences, Engineering, and Medicine, 2018: Thriving on Our Changing Planet: A Decadal Strategy for Earth Observation from Space. National Academies Press, 716 pp., https://doi.org/10.17226/24938.

Nieman, S., J. Schmetz, and P. Menzel, 1993: A comparison of several techniques to assign heights to cloud tracers. J. Appl. Meteor., 32, 1559-1568, https://doi.org/10.1175/ 1520-0450(1993)032<1559:ACOSTT>2.0.CO;2.

Nieman, S. J., W. P. Menzel, C. M. Hayden, D. Gray, S. Wanzong, C. S. Velden, and J. Daniels, 1997: Fully automated cloud-drift winds in NESDIS operations. Bull. Amer. Meteor. Soc., 78 , 1121-1134, https://doi.org/10.1175/1520-0477(1997)078<1121: FACDWI $>2.0 . \mathrm{CO} ; 2$.

Posselt, D. J., G. L. Stephens, and M. Miller, 2008a: CloudSat: Adding a new dimension to a classical view of extratropical cyclones. Bull. Amer. Meteor. Soc., 89, 599-609, https:// doi.org/10.1175/BAMS-89-5-599.

_ T. S. L'Ecuyer, and G. L. Stephens, 2008b: Exploring the error characteristics of thin ice cloud property retrievals using a Markov chain Monte Carlo algorithm. J. Geophys. Res., 113, D24206, https://doi.org/10.1029/2008JD010832.

Putman, W., A. M. da Silva, L. E. Ott, and A. Darmenov, 2014: Model configuration for the 7-km GEOS-5 nature run, Ganymed Release: Non-hydrostatic 7 km Global Mesoscale Simulation. GMAO Office Note 5 (Version 1.0), 18 pp., https://gmao.gsfc.nasa.gov/pubs/docs/Putman727.pdf.

Rabier, F., H. Järvinen, E. Klinker, J. Mahfouf, and A. Simmons, 2000: The ECMWF operational implementation of fourdimensional variational assimilation. I: Experimental results with simplified physics. Quart. J. Roy. Meteor. Soc., 126, 1143 1170, https://doi.org/10.1002/qj.49712656415.

Rawlins, F., S. P. Ballard, K. J. Bovis, A. M. Clayton, D. Li, G. W. Inverarity, A. C. Lorenc, and T. J. Payne, 2007: The Met Office global four-dimensional variational data assimilation scheme. Quart. J. Roy. Meteor. Soc., 133, 347-362, https://doi.org/ 10.1002/qj.32.
Rodgers, C. D., 2000: Inverse Methods for Atmospheric Sounding: Theory and Practice. World Scientific, $256 \mathrm{pp}$.

Salonen, K., J. Cotton, N. Bormann, and M. Forsythe, 2015: Characterizing AMV height-assignment error by comparing best-fit pressure statistics from the Met Office and ECMWF data assimilation systems. J. Appl. Meteor. Climatol., 54, 225242, https://doi.org/10.1175/JAMC-D-14-0025.1.

Santek, D., 2010: The impact of satellite-derived polar winds on lower-latitude forecasts. Mon. Wea. Rev., 138, 123-139, https:// doi.org/10.1175/2009MWR2862.1.

_ S. Nebuda, and D. Stettner, 2014: Feature-tracked winds from moisture fields derived from AIRS sounding retrievals. 12th Int. Winds Workshop, Copenhagen, Denmark, EUMETSAT, https://www.eumetsat.int/website/wcm/idc/idcplg?IdcService $=$ GET_FILE\&dDocName=PDF_CONF_P61_S2_03_SANTEK_ $\mathrm{P} \&$ RevisionSelectionMethod $=$ LatestReleased $\&$ Rendition $=$ Web.

Schmetz, J., K. Holmlund, J. Hoffman, B. Strauss, B. Mason, V. Gaertner, A. Koch, and L. Van Der Berg, 1993: Operational cloud motion winds from METEOSAT infrared images. J. Appl. Meteor., 32, 1206-1255, https://doi.org/10.1175/15200450(1993)032<1206:OCMWFM>2.0.CO;2.

Skamarock, W. C., and Coauthors, 2008: A description of the Advanced Research WRF version 3. NCAR Tech. Note NCAR/TN475+STR, 113 pp., https://doi.org/10.5065/D68S4MVH.

Stewart, T. R., C. M. Hayden, and W. L. Smith, 1985: A note on water-vapor wind tracking using VAS data on McIDAS. Bull. Amer. Meteor. Soc., 66, 1111-1115, https://doi.org/10.1175/ 1520-0477(1985)066<1111:ANOWVW > 2.0.CO;2.

Velden, C. S., and K. M. Bedka, 2009: Identifying the uncertainty in determining satellite-derived atmospheric motion vector height attribution. J. Appl. Meteor. Climatol., 48, 450-463, https://doi.org/10.1175/2008JAMC1957.1.

, C. M. Hayden, S. Nieman, W. P. Menzel, S. Wanzong, and J. Goerss, 1997: Upper-tropospheric winds derived from geostationary satellite water vapor observations. Bull. Amer. Meteor. Soc., 78, 173-195, https://doi.org/10.1175/ 1520-0477(1997)078<0173:UTWDFG >2.0.CO;2.

, and Coauthors, 2005: Recent innovations in deriving tropospheric winds from meteorological satellites. Bull. Amer. Meteor. Soc., 86, 205-223, https://doi.org/10.1175/BAMS-86-2-205.

Wu, T., H. Liu, S. J. Majumdar, C. S. Velden, and J. L. Anderson, 2014: Influence of assimilating satellite-derived atmospheric motion vector observations on numerical analyses and forecasts of tropical cyclone track and intensity. Mon. Wea. Rev., 142, 49-71, https://doi.org/10.1175/MWR-D-13-00023.1.

Wu, Q., H. Wang, Y. Lin, Y. Zhuang, and Y. Zhang, 2016: Deriving AMVs from geostationary satellite images using optical flow algorithm based on polynomial expansion. J. Atmos. Oceanic Technol., 33, 1727-1747, https://doi.org/ 10.1175/JTECH-D-16-0013.1.

Zeng, X., S. Ackerman, R. D. Ferraro, T. J. Lee, J. J. Murray, S. Pawson, C. Reynolds, and J. Teixeira, 2016: Challenges and opportunities in NASA weather research. Bull. Amer. Meteor. Soc., 97, ES137-ES140, https://doi.org/10.1175/ BAMS-D-15-00195.1. 